\title{
Performance Analysis of IOT based Flood Monitoring Framework in Sub-urban
}

\author{
*Annisa Jamali \\ Faculty of Engineering \\ Universiti Malaysia Sarawak \\ Sarawak, Malaysia \\ jannisa@unimas.my
}

\author{
Jonathan Peter Giman \\ Faculty of Engineering \\ Universiti Malaysia Sarawak \\ Sarawak, Malaysia \\ nathjhon97@gmail.com
}

\begin{abstract}
Flooding is the most common natural catastrophe worldwide that occurred without warning which caused great destruction. The government has spent millions of monies on flood mitigation plans. Several systems had been proposed which some of them have been employed around the country. However, it is limited to selected areas due to high installation and maintenance costs. This paper investigates two potential real-time flood monitoring frameworks in the sub-urban area, which are simpler, inexpensive, and require minimum maintenance. The proposed flood monitoring system utilized wireless data transmission system that is either GSM SIM900A module or XBee Pro module. The data was sent to NodeREd for monitoring purposes. From the result, XBee Pro can send more, and faster data as compared to GSM module. The time delay is very much lower for XBee Pro whereby the difference of realtime data captured as compared to the setup time interval that had been set in the system. In terms of consistency and sensitivity, both systems have equal efficacy. In Summary, both systems are adequate to offer monitoring and immediate warning in real-time. However, XBee pro is preferable if the area has internet access. Meanwhile, if the internet service is limited, GSM module can be a good alternative since it does not need Internet access.
\end{abstract}

Keywords-flood monitoring, Internet of Things, warning system, water level; disaster risk reduction.

\section{INTRODUCTION}

For the past few decades, flooding is one of the main tragedies in the world and today, it is commonly occurred in Malaysia. Climate differences, land usages, population increasing and uncontrolled activities especially deforestation and water structure construction, are causing changes in flood forms [1]. Malaysia has an average rainfall of about 2,500 $\mathrm{mm}$ per year, $3000 \mathrm{~mm}$ per year in Sabah and $3500 \mathrm{a} \mathrm{mm}$ in Sarawak per year [2-3], thus resulting in a frequent natural catastrophe in Malaysia [4].

The disasters have been grouped by Department of Irrigation and Drainage (DID), Malaysia into two categories which are flash floods and monsoon floods [5]. From the hydrological point of view, the distinction between flash floods and monsoon floods is based on the amount of time taken to return to its regular position through the water [6]. Flows can be reasonably expected excluding flash floods, which often have far less confidence in terms of scale and design. Flash flooding is unpredictable and happens except for advance warnings that scare people during their daily events and hit people who are mostly on their way. Monsoon floods are activated between November and March by Northeast monsoon winds, while the Southwest monsoon winds are triggered between May and September [7].

Over recent years, there have been frequent natural disasters in Malaysia as a result of weather, particularly floods and landslides, resulting in deaths and property injuries. On 30
October 2010 to 11 November 2010, and from 30 January 2011 to 15 February 2011, the floods occur in Peninsular Malaysia triggered the displacement of 231.337 casualties from 57.094 families to 906 evacuation centers and the death of 21 human beings [8]. About 29,000 square $\mathrm{km}$ or $9 \%$ of the region of the country submerged which affected many people [9]. The current situation has become more difficult as, in compliance with the data released by Malaysia Meteorological Department (MMD), it has been noticed that the population of the Malaysian area is progressively susceptible to natural disasters due to a severe local weather transition [8]. It effects both urban and suburban areas. For instance, a flood tragedy happened in Kelantan in 2014 and Pahang in 2021 which affected almost all over state caused a lot of damages. Besides, in year 2019, Baram, Miri was reported having a severe flood in which affected thousands of villagers and government hospitals and schools. These situations proved that the framework for setting the flood alarm in certain places is not environmentally responsive system or worst case it is non-existing.

Many developed countries such as the United States, Japan, China, and so on have been implemented this system throughout all high threat and affected areas in their nations. In contrary, not many countries particularly third-world countries have flood warnings and monitoring systems in place. In Malaysia, there are only some places especially cities but rarely in outskirts, that used the existing system to monitor the water level [10]. This flood alerting and monitoring system, alongside surveillance and data collection, it will warn people more easily at an early stage to encourage them, before the flood becomes more severe, to save their property and families. The emerging flood monitoring system is now becoming increasingly popular among the countries as the consequences of the flood catastrophe will cause a huge loss of money and even people's lives.

Flood monitoring system can be categorized into three main groups that are, non-wireless-based systems, wireless (data) based systems, and wireless visual-based systems. Labo et. Al [11] have proposed a flood monitoring and warning system with automatic emergency lighting for Barangay Salog River, Sorsogon City to assist the community in disaster prevention and disaster preparedness. The system consists of automated emergency lighting and lights when power failures operated by rechargeable sealed batteries are supplied by ac energy to the unit automatically. The system used a nonwireless setting. Another wired system proposed by Debbarma,S [12] was utilizing an FPGA board in which the sensors were used to measure real-world parameters including water pressure, water level, wind, temperature, etc. This unit was installed in the river so that the sensor can always detect water levels. The output results were obtained and displayed on the LCD as well. The system works well and other benefits from this system are low power consumption and high 